\title{
Study of Coatings Intended for Active Parts of Forming Tools Produced by Powder Metallurgy
}

\author{
Elena Kantoríková (0000-0003-3615-4565), Ján Moravec (0000-0003-4588-2230) \\ Faculty of Mechanical Engineering, University of Zilina, Univerzitna 8215/1, 01026 Žilina, Slovakia, E-mail: \\ elena.kantorikova@fstroj.uniza.sk,jan.moravec@fstroj.uniza.sk
}

The article deals with new types of coatings and their mechanical properties. CTRN and CRONAL are newly developed coatings intended for active parts of forming tools. Their behavior and mechanical properties are still under investigation. Coatings are used for functional components in various areas of industries, their development is constantly in process. The aim of the study and the experimental solution provides a comparison of the mechanical properties of the new coatings with the well-known coatings DLC, TiN and TiSiN. The aim of the work was to perform an analysis of CTRN and CRONAL coatings and compare their mechanical properties with other coatings. We chose the methods of nanoindentation, hardness measurement, scratch test and layer roughness. The results will allow easy determination of the proper coating for a suitable material. The results present the specific functionality of the individual coatings.

Keywords: Coating, Active parts tool, Mechanical properties, KTRN, CRONAL

\section{Introduction}

A coating is a thin layer of material that is applied to the surface of the substrate. Its purpose can be functional or decorative [1]. Functional coatings are applied to protect the substrate or to improve its mechanical, sliding or other physical and chemical properties. Investigation of mechanical properties of coatings is still a current topic [2]. The scientific community is still involved in the development of new surface layers. The use of surface layers and coatings is mostly monitored in tribological processes [3].

The technical role of coatings is to optimize production technologies while minimizing losses caused by friction and wear [4]. The development of coatings has undergone enormous changes in recent decades [5] - from simple single-layer to multi-layer coatings, through gradient and advanced adaptive coatings [6]. Coatings can ensure low friction, increased adhesion, reduced mechanical and chemical noncompliance between substrate and coating, ability to halt crack propagation during operation in harsh or demanding conditions, adaptability to changing operating conditions, and increased hardness or toughness [7, 8]. The application of thin, wear-resistant hard coatings expands to various industries to provide protection for tools and other components from damage due to wear and corrosion [9 - 11].

\subsection{Coating of forming tools}

However, finding coated forming tools in the domain of forming processes is still an exception rather than a rule. In the tribosystem, it is necessary to accept not only the mechanical properties of the formed material, but also its surface treatment [10]. Applications of thin hard coatings improve the quality of moldings, can reduce wear and enable the elimination of longterm and costly production downtime caused by tool damage $[10,11]$. Surface treatment of materials clearly improves the quality of products. Surface treatment of forming tools such as punches (cutters), molds, benders, dies and lower dies using PVD (physical vapor deposition) coatings with low friction and high hardness provides increased durability and productivity $[12,13]$. The thin coating layer prevents the cut material from sticking to the punch, facilitates the pulling out of the cut material when the punch is retracting, and prevents the tool from seizing up. The coating process takes place at a temperature up to 200 to 300 ${ }^{\circ} \mathrm{C}$. It is possible to coat tools and molds made of tool steels that have a tempering temperature after hardening of 200 to $300{ }^{\circ} \mathrm{C}$ without loss of hardness (58 to 62 HRC).

\subsection{Coating technology}

Coating technologies are the subject of continuous research because they are essential for the realization of innovative products [13]. Experimental coatings were formed by the method of thin layers applied in a vacuum, using methods of the so-called plasma cathodic evaporation and magnetron sputtering. This method of deposition takes advantage of the fact that the arc discharge burns at low pressure on the cathode, evaporates the cathode material at high temperature, and most of it is ionized [14, 15]. The cathode spot movement can be controlled by a magnetic field [16, 
17]. The deposition of the layers is based on spraying the cathode material by energetic ions and condensing the particles of the sputtered-away material on the substrate. A frequently used PVD method based on the sputtering principle is the so-called magnetron sputtering. Due to the high voltage, a discharge forms in an inert gas atmosphere. High-energy gas ions bomb the target - cathode. Impulse transfer induces cascading pulses on the surface of the target, resulting in sputtering of the material without a transient liquid phase. Magnetic field extends the path of electrons, and permanent magnets arranged behind the target enable to influence the shape of the transfer (sputtering) of the material $[17,18]$.

\section{Materials and methods}

For the experimental analysis, three types of steel produced by third-generation powder metallurgy were selected. These steels are 1.2379, S390 and Vanadis 4 - they are commonly used to manufacture forming tools. These steels were selected because of their frequent use in tribological systems. All three steels are characterized by their high resistance to wear and pressure. They are used for forming tools with requirements for hardness and heat abrasion resistance, and also for cutting tools for machining or highly stressed molds. They are characterized by high hardness and strength [17]. They can be machined in both soft and hard condition and offer advantages in the manufacture and maintenance of tools $[18,19]$.

The basic material consists of a ledeburitic structure, only the content and size of chromium particles change. Material 1.2379 contains large and coarse grains of chromium, S390 is a mixture of carbides with finer chromium and tungsten. Vanadis contains a large amount of small chromium carbides (Fig. 1).

The coatings examined were selected based on their ability to affect the mechanical wear of the sample. The calotest method was used to determine thickness of the coatings. The layer of each coating examined was accurately inspected by observing the crater of the bead. The choice of the thickness of coatings on tools is one of the most important characteristics in terms of application, as it affects the durability of the tool and must be adapted to the intended use of the tool.

Coatings having well-defined and repeatable properties were applied to each experimental material. They improve the behavior and performance of tools.

DLC - diamond like carbon. It is a carbon-based layer with high frictional resistance. The layer is formed by the PACVD method (plasma assisted chemical vapor deposition), which is the coating of instruments at lower temperatures than conventional CVD (chemical vapor deposition) techniques. The tools were coated only after the final heat treatment to the required hardness, and there are no dimensional changes during the coating process. The basic properties of DLC include high chemical resistance, electrical nonconductivity and low coefficient of friction. Fig. 1 shows a DLC monolayer on a base matrix. On the right is the trace from which the layer thickness is determined. The DLC coating is dark gray in color, with good adhesion to the base material. Its thickness is $0.95 \mu \mathrm{m}$.

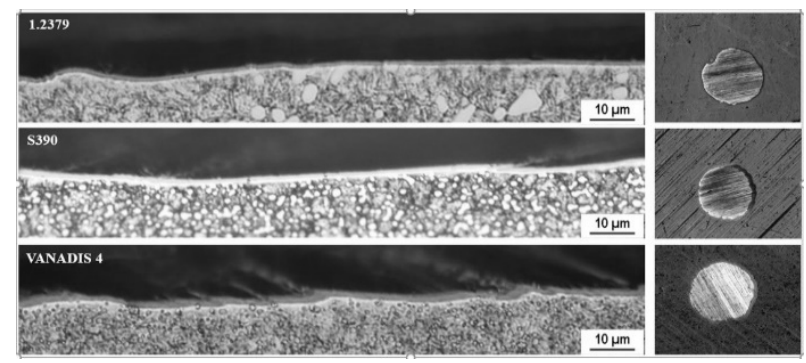

Fig. 1 This is an Experimental DLC coating

TiN - titanium nitride. It is the most commonly used coating. It reduces friction, increases chemical and thermal resistance, edge retention and reduces build-up formation, especially when machining mild steels. TiN is suitable for coating tools made of sintered carbides and from tool steels - drills, cutters, taps, reamers, cutting blades, knives, cutting tools, benders, molds, etc. It can also be used for coating medical instruments (surgical and dental) and various implants due to its biocompatibility. It has also found wide application as a decorative coating thanks to its deep golden color. The advantage is that the worn TiN coating can be removed from tool steels. Repair of worn tools and subsequent coating of a new layer significantly reduces costs compared to the purchase of new tools $[19,20,21]$. TiN coating is yellow (Fig. 2). The adhesion depends on the chemical composition and allows easy layer formation - the monolayer is $1.55 \mu \mathrm{m}$ thick.

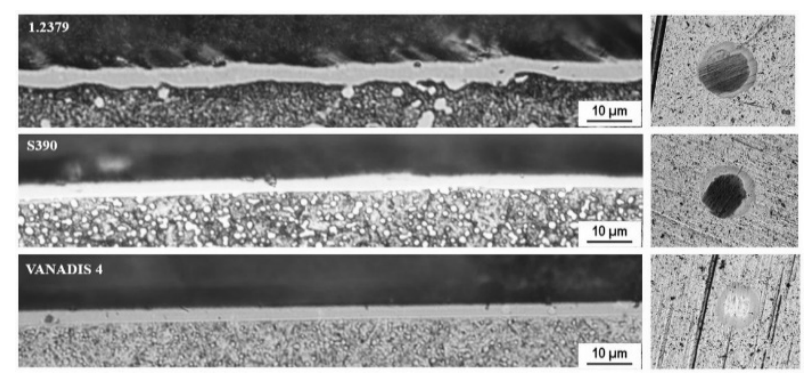

Fig. 2 This is an Experimental TiN coating

TiSiN - titanium silicon nitride. It is intended for high-speed machining of hard materials under minimal or zero lubrication conditions. The coating is designed to achieve heat resistance up to $1100^{\circ} \mathrm{C}$. TiSiN is a multilayer coating with a nano-composite outer layer with Si3N4 nanocrystals in a crystalline TiN matrix. This matrix is designed to protect the cutting 
edge from heat transfer, oxidation and abrasion [20]. The trace on the right reveals that the yellow color of the layer is only on the surface (Fig. 3). The brown TiSiN multilayer is $1.6 \mu \mathrm{m}$ thick.

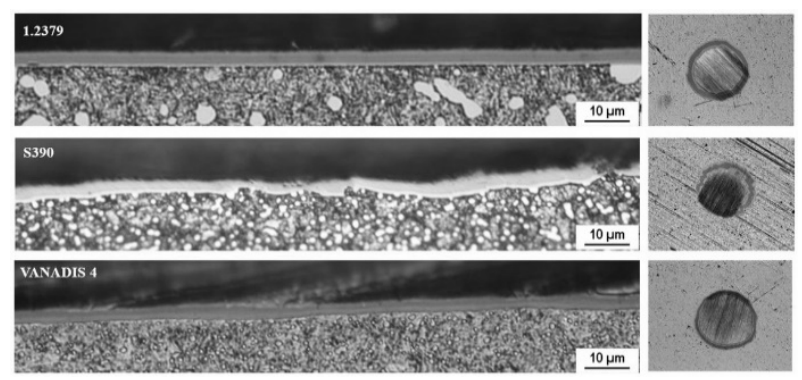

Fig. 3 This is an Experimental TiSiN coating

CTRN - composite temperature resistant nitride. CTRN is a universal coating designed for machinable steels, stainless steels and cast irons, which are used for extremely difficult cutting conditions. It was developed for solid carbide cutters, drills and cutting blades to be used in $\mathrm{CNC}$ machining centers. CTRN is suitable for applications where high chemical and thermal resistance is required (above $900{ }^{\circ} \mathrm{C}$ ). New composite coatings based on $\mathrm{Al}, \mathrm{Ti}, \mathrm{Si}, \mathrm{Nb}$ and $\mathrm{Cr}$ produced by the new ARC technology achieve thermal resistance to oxidation up to $1000{ }^{\circ} \mathrm{C}$. The achieved hardness is approximately $3500 \mathrm{HV}$ and the adhesion of coatings is $100-120 \mathrm{~N}$ [20 - 22]. The dark gray monolayer is 1.55 $\mu \mathrm{m}$ thick (Fig. 4).

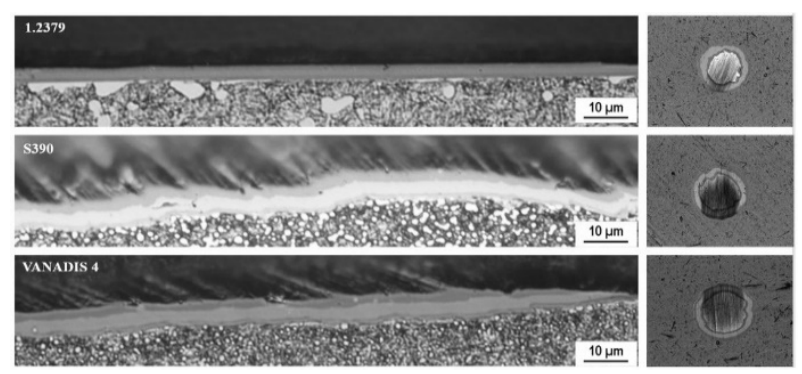

Fig. 4 This is an Experimental CTRN coating

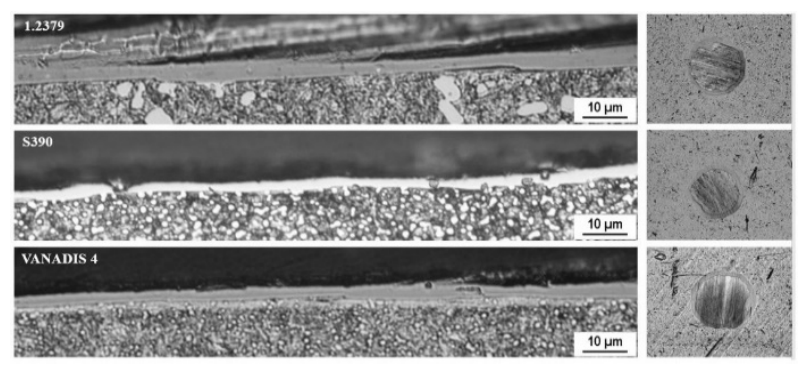

Fig. 5 This is an Experimental CRONAL coating

CRONAL - chromium aluminum nitride. It is a specially developed coating for extremely difficult cutting conditions when machining heat treated steels. The coating is also more resistant to corrosion. CRONAL maintains a stable structure at temperatures up to $900{ }^{\circ} \mathrm{C}[20$ - 22]. It has a light gray color and is applied as a multilayer. Measured thickness is $1 \mu \mathrm{m}$ (Fig. 5).

The coatings have different chemical compositions and structures than the substrate material. This creates an interface with a significant change in physical-mechanical and chemical properties, which can cause problems both in the formation of coatings and in their application. Layers and coatings affect mechanical wear, corrosion, thermal insulation, compatibility, electrical conductivity, and optical characteristics such as reflection, absorption, and surface color. The surface layers modify the chemical composition and structure of surface and subsurface layers of the substrate material. The thickness of the coatings also affects the tool life. Tab. 1 shows the thicknesses (in $\mu \mathrm{m})$ of the layers used.

Tab. 1 The thickness of the coatings, Calotest

\begin{tabular}{cccccc}
\hline Coatings & DLC & TiN & TiSiN & KTRN & Cronal \\
\hline $\begin{array}{c}\text { Thick- } \\
\text { ness } \\
{[\mu \mathrm{m}]}\end{array}$ & 0.95 & 1.55 & 1.6 & 1.55 & 1 \\
\hline
\end{tabular}

\subsection{Nanoindentation}

Depth sensing indentation - nanoindentation, is one of the methods of materials research. Materials are investigated by nanoindentation in order to be able to compare changes in mechanical properties over different time periods. Low load and displacement values are recorded. Using an analytical model, load and displacement data can be used to determine hardness and other mechanical properties [20, 23, 24]. The results from nanoindentation are shown in the graph (Fig. 6). The hardness of the coating affects the base material. The same coating has different hardness on different materials. The DLC coating has the lowest hardness. It ended up as soft in our experiment despite the fact that it belongs to hard coatings. TiSiN on Vanadis steel achieved the highest hardness and CTRN is similar to it. CRONAL manifests higher hardness than TiN. We assume that the resulting hardness was affected by the chromium and titanium contents in the coatings. However, the properties of the coating can also be affected by a change in the stress used during deposition.

Indentation parameters: Acquisition rate: 10.0 [Hz], Approach speed: $3000 \mathrm{~nm} / \mathrm{min}$, Maximum load: $3.00 \mathrm{mN}$, Stiffness threshold: $500 \mu \mathrm{N} / \mu \mathrm{m}$, Material: Diamond.

Scratch test is a technology of tribological testing of coated materials. To maximize the potential of the coatings, it is necessary to ensure maximum adhesion of the layer to the substrate. Each tool must be prepared before coating. Good coating application depends 
on the adhesion of the material $[21,25,26]$. The measurement principle consists in applying a loading force F to a steel tip while moving the top of the tip along the layer to be measured. When measuring the coating layer, the acoustic emission is defined, which changes when the layer is completely removed. The measured values are given in $\mathrm{N}$. The adhesion test is performed using the Scratch test. Adhesion depends on the total thickness of the coating. The force capable of removing the surface layer is measured. Figure 7 shows the friction paths. Values are recorded from the first damage to the layer to the complete failure of the coating.

The results obtained are shown in Fig. 8. This is the deformation of the coating from zero load to complete loss of the coating layer. The end of the blue line represents the beginning of the loss of coating integrity. The end of the red line is the complete loss of the coating from the material. For example, it is necessary to use a force of $36 \mathrm{~N}$ to destroy the CRONAL coating on Vanadis steel, and at $42 \mathrm{~N}$ the coating is completely removed from the steel substrate.

It is clear from the results that the DLC coating has the longest service life, although it is the softest of the investigated coatings. As in the previous case, the importance of the chosen substrate material was confirmed. The measurements show that the CRONAL coating is similar to the DLC coating, as the deformation does not begin until the force of $36 \mathrm{~N}$. The high frictional resistance of the coatings was confirmed here. It is assumed that the above is caused by an increased content of chromium and aluminum. The CTRN layer, like TiSiN, manifests itself equally in all steels examined. They manifest a shorter service life compared to other coatings, which can be caused by wt. \% $\mathrm{Ti}$ and $\mathrm{Si}$ content in the investigated material.

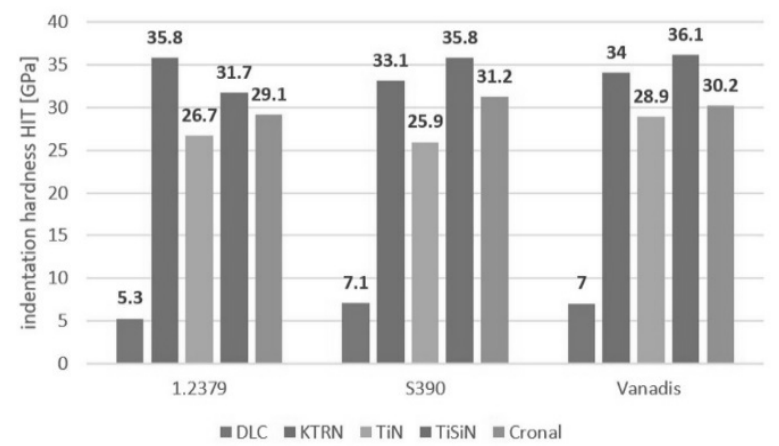

Fig. 6 Comparison of coating hardness

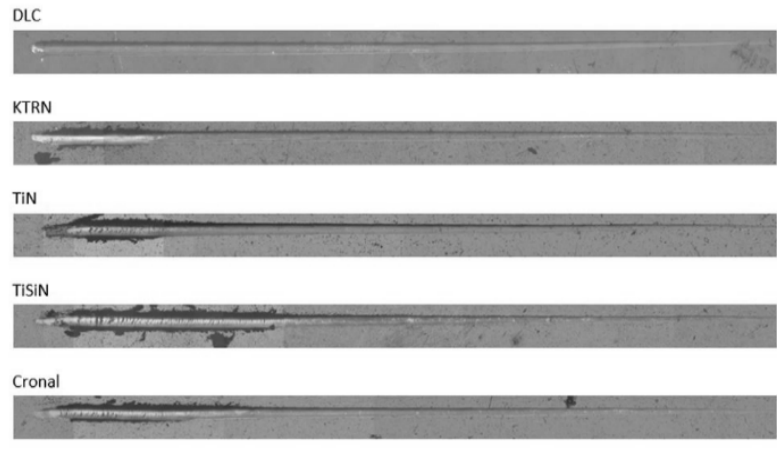

Fig. 7 Scratch Test - deformed coatings on material 1.2379

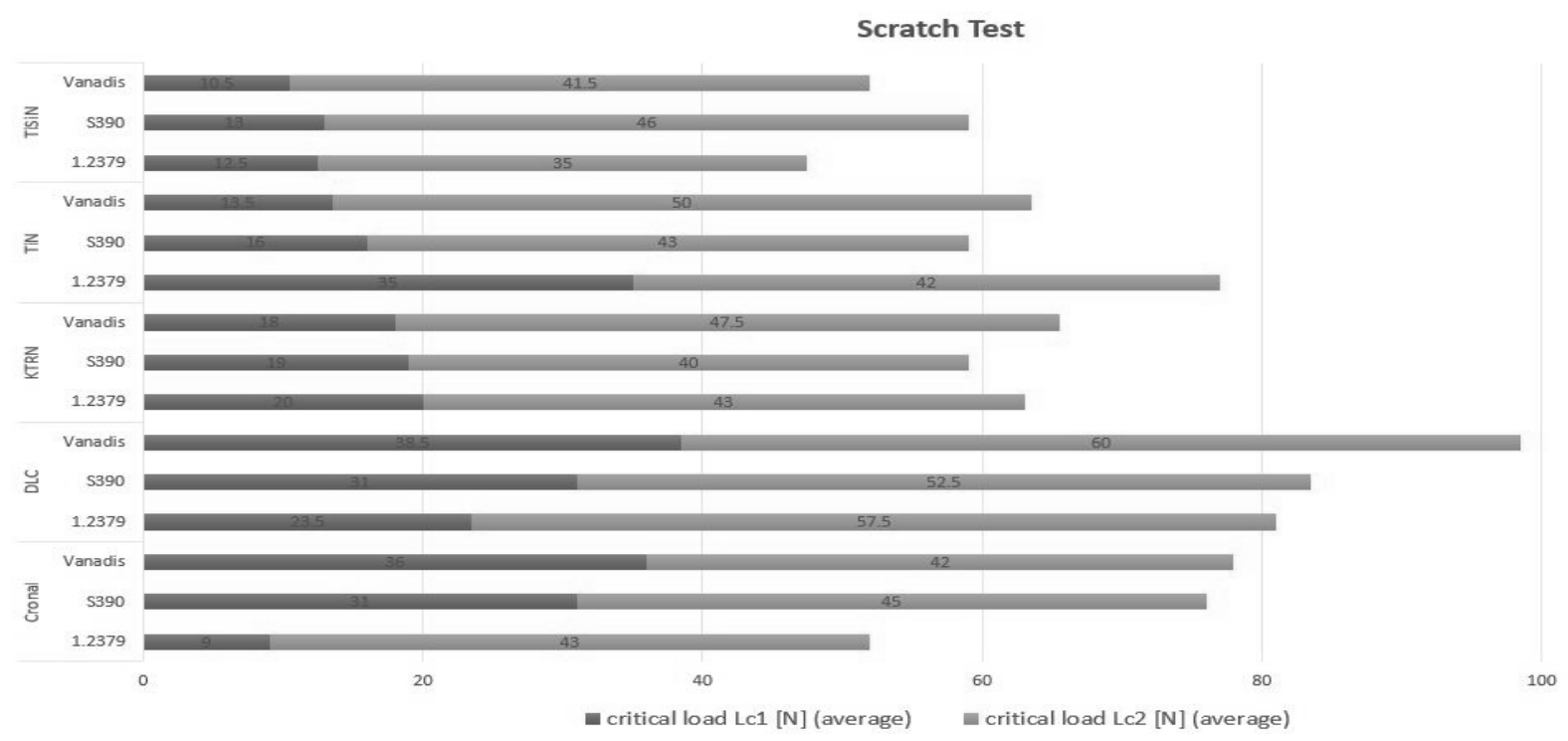

Fig. 8 Scratch test - deformations of the coating, dependence of force $[N]$ on time $[s]$. Lc1 ... first cracks and layer damage. Lc2... complete coating failure

\subsection{Roughness of coatings}

Roughness of coatings depends on the manufacturing technology used. It is an uneven surface with small distances. During coating, its roughness is caused by the quality of applying the coating material. Surface roughness is conditioned by the thermal and mechanical stress of the tool. There is always an effort to eliminate increased roughness either by modifying 
the coating technology or by additional modification of tools after coating. Roughness measurement is performed on polished substrates [22, 27, 28]. Roughness affects fatigue strength, wear resistance, anti-corrosion stability, fitting quality, etc. It is monitored for dynamically stressed components that are more susceptible to surface failure. Comparison of measured roughness values is plotted in the graph (Fig. 9), where Ra is the mean arithmetic deviation of the surface.

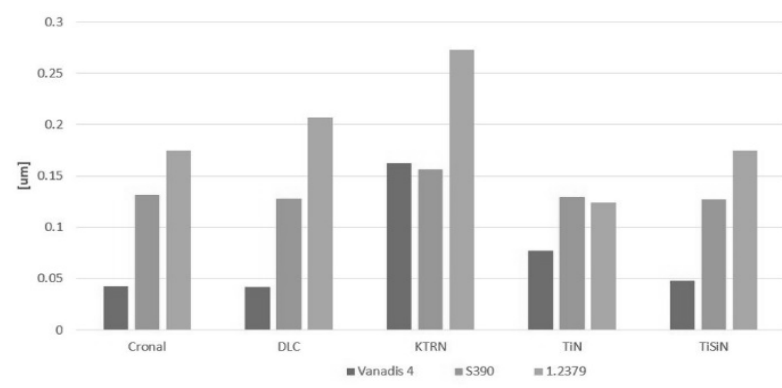

Fig. 9 Comparison of the average roughness of the tested coatings

According to Fig. 9, the coatings applied to 1.2379 steel have the highest roughness. This result corresponds to the adhesion found by the scratch test. CTRN dominates among the coatings due to the advantage of its application that facilitates the manufacturing technology. The lowest roughness is shown by DLC on Vanadis steel. To some extent, the roughness investigated is affected by the surface of the material on which the coating is deposited. According to our findings, 1.2379 appears to be steel with a higher roughness compared to S390 and Vanadis steels. The roughness obtained may be related to the structure of the steels, where Vanadis has fine chromium carbides, while in 1.2379 steel the chromium carbides are coarse grains (see Fig. 1 to 5). Coating roughness is important due to friction and wear resistance for heavily stressed components or for highspeed sliding parts.

\section{Conclusions and recommendations}

The application of thin, hard, wear-resistant coatings expands to various industries to provide protection for tools and other components from damage due to wear and corrosion. The aim of coating development is to prevent or at least reduce material losses and achieve energy, environmental and economic savings. Experimental analysis of the coatings shows that:

Nanoindentation confirmed the importance of which coating is applied on which substrate material. The highest hardness is manifested in CTRN (39.8 $\mathrm{GPa}$ ) and TiSiN (36.1 GPa), followed by CRONAL $(31.2 \mathrm{GPa}$ ) and TiN (28.9 GPa), the last being DCL $(7.1 \mathrm{GPa})$. Hardness depends on the chemical compo- sition. Hardness characterizes the resistance of the layer to damage by other objects.

Scratch test evaluates DCL as a coating with the longest service life. Failure occurred at $60 \mathrm{~N}$. The fastest deformed layer was TiSiN on 1.2379 steel, where the coating disappeared at $35 \mathrm{~N}$.

The coating with the highest roughness is CTRN with $2.89 \mu \mathrm{m}$, those with the lowest roughness are DLC and CRONAL with $0.04 \mu \mathrm{m}$.

Coatings are used for functional components in various areas of industries, their development is constantly in process. Each of the coatings has its specific properties and different degree of functionality, and therefore it is not possible to say unambiguously which coating has the best properties.

\section{Acknowledgement}

This work was supported by project KEGA 022ŽU-4/2021 by Scientific Grant Agency of Ministry of Education of Slovak Republic.

\section{References}

[1] SHARIFAHMADIAN, O., MAHBOUBI, F. (2019). Ceramics International, Comprehensive tribological study of optimized N-DLC/DLC coatings fabricated by active screen DC-pulsed PACVD technique. 16424-16432

[2] XI-CHENG, W., FU RY, LI L. (2007). Surface and Coatings Technology 201:6922-6927.

[3] ZDRAVECKÁ, E., ONDÁČ, M. (2012). Tribológia pourchových vrstiev. Košice. Technická univerzita v Košiciach. 25 s. il. ISBN 978- 80-553$0885-2$

[4] BEWILOGUA, K., BRAUER, G., DIETZ, A., GABLER, J., GOCH, G., KARPUSCHEWSKI, D., SZYSZK, B. (2009). Surface technology for automotive engineering. CIRP Annals - Manufacturing Technology 58 608-627 http: / / ees.elsevier.com/cirp/default.asp

[5] OERLIKON BLAZERS. (2015). www.oerlikon.com. http://www.oerlikon.com/balzers/cz/

[6] OSAKADA, I., K., MATSUMOTO, R. (2000). Annals of the CIRP Vol. 49. Fundamental Study of Dry Metal Forming with Coated Tools.

[7] WUHRER, R., YEUNG, WY. (2004). Scripta Mater. A comparative study of magnetron cosputtered nanocrystalline titanium aluminium and chromium aluminium nitride coatings.

[8] LUO, D. B.; FRIDRICI, V.; KAPSA, P. (2011). Wear. A systematic approach for the selection 
of tribological coatings. pp 271(9 - 10): 2132 2143.

[9] DIVJAK, A., MODRIČ, D., KOVAČIČ, I., CVILJUŠAC, V. (2020). Technical Gazeette. Anisotropic Mechanical Properties of Materials in Stereolithographic Additive Manufacturing. ISSN 1330-3651. pp 1748-1753.

[10] HANZL. P, ZETKOVÁ, I., KUČEROVÁ, L. (2019). Manufacturing Technology. Vol. 19, No. 1. pp. 37-41. Structural Changes and Microstructure of Maraging Steel Lattice Structures using Additive Manufacturing. ISSN 1213-2489.

[11] IHI IONBOND. (2015). IHI Engineering Review. https://www.ihi.co.jp/var/ezwebin_site/storage/original/application/5c70fac9d611ceaeab26a4f6c7c6ff6e.pdf.

[12] BEWILOGUA, K., BRÄUER, G., DIETZ, A., GÄBLER, J., GOCH, G., KARPUSCHEWSKI, B., SZYSZKA, B. (2009). Manufacturing Technology. Surface technology for automotive engineering, CIRP Annals, pp 608-627.

[13] ALI, H., YERBOLAT, G. ABILGAZIYEV, A., (2020). Manufacturing Technology. Vol. 20, No.2. pp. 135-142. Modeling and Simulation of Composite Materials for SLS-Based 3D Printing. ISSN 1213-2489. DOI: $10.21062 / \mathrm{mft} .2020 .041$

[14] SIVARAJAN, S., PADMANABHAN, R. (2015). Journal of Chemical and Pharmacentical Sciences. pp. 381 - 385. Surface engineered coatings for automotive industries. ISSN: 09742115.

[15] ZHANG X. et al. (2018). Prog. Mater. Sci., vol. 96, pp. 217-321. Radiation damage in nanostructured materials.

[16] YU, K. Y.et al. (2012). J. Nucl. Mater., vol. 425, no. 1-3, pp. 140-146. "Radiation damage in helium ion irradiated $\mathrm{n}$ anocrystalline Fe."

[17] HOLMBERG, K. ERDEMIR, A. (2017). Costs Emiss. 5 pp 263-284. Influence of tribology on global energy consumption. https://link.springer.com/article/10.1007\%2Fs40544-0170183-5

[18] NOWAK, B., JANUSZEWICZ, P. (2017). Surf. Coating.Technol. 329 pp 1-10. Surface \& coatings technology mor-phology, mechanical and tribological properties of hybrid carbon la- yer fabricated by radio frequency plasma assisted chemical vapor deposition. https://doi.org/10.1016/j.surfcoat.2017.09.001.

[19] BANERJI, A. BHOWMICK, B., ALPAS, A.T. (2014). Surf.Coatings Technol. 241 pp 93-104. High temperature tribological behavior of Wcontaining diamond-like carbon (DLC) coating against titanium alloys.

[20] PRŮCHA, V., BRICIN, D., KŘIŽ, A. (2019). Manufacturing Technology. Vol. 19, No. 1. pp. 129134. Effect of Cryogenic Treatment on Properties of Cemented Carbides. ISSN 1213-2489

[21] BÖHLER S290 - steel. http://www.nozenuz.com/nozirske_oceli/s290.php

[22] VOESTALPINE. Uddeholm Vanadis 4 Extra SuperClean. https://www.uddeholm.com/slovakia/sk/products/uddeholm-vanadis-4-extrasuperclean-2/

[23] EMUGE - FRANKEN. (2004). Handbuch der Gewindetechnik und Frästechnik. Anwendungen Tipps - Tabellen. Germany.

[24] STATON s.r.o Turany. (2019). Ponuka povlakov. http://www.staton.sk/sluzby/povlakovanie/nasa-ponuka-povlakov/

[25] KONAR, R., MICIAN, M. (2019). Archives of Metallurgy and Materials, Vol. 64, Iss. 1, p. 353357. Material ultrasonic attenuation influence on conventional ultrasonic non-destructive Copper alloy cast testing., ISSN 1733-3490, DOI: 10.24425/amm.2019.126259

[26] PASTIRCAK, R., SCURY, J., BRUNA, M., BOLIBRUCHOVA, D. (2017). Archives of foundry engineering, Vol. 17, Iss. 2, pp. 75-78. Effect of Technological Parameters on the AlSi12 Alloy Microstructure during Crystallization under Pressure. ISSN 2299-2944

[27] DEMBICZAK, T., BALAGA, Z., OPYDO, M., KRUZEL, R., GARBIEC, D., DYNER, M. (2021). Manufacturing Technology. Vol. 21, No. 1. pp. 45-50. The Effect of the Binder Phase and Sintering Temperature on the Properties of Spark Plasma Sintering WC-Co Cemented Carbides. ISSN 1213-2489. DOI: $10.21062 / \mathrm{mft} .2021 .002$

[28] PRŮCHA, V., BRICIN, D., KŘIŽ, A. (2019). Manufacturing Technology. Vol. 19, No. 1. pp. 129134. Effect of Cryogenic Treatment on Properties of Cemented Carbides. ISSN 1213-2489 